EDITORIAL

\title{
Editorial
}

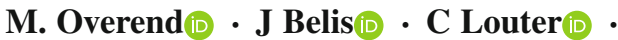

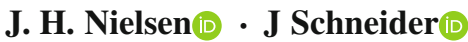

Published online: 9 July 2020

(C) Springer Nature Switzerland AG 2020

The breadth and depth of the papers handled by this journal since its first edition in 2016 is astounding and is a testament to the vibrant field of glass engineering and to the dedicated work of researchers, reviewers and the editorial team. To celebrate and recognise the excellence of the papers published in Glass Structures $\&$ Engineering, we are establishing a best paper award with the generous support of our publisher. The annual award will be conferred to one paper from those published in a particular calendar year. The paper will be selected by the editors-in-chief on the basis of its scientific quality and/or practical significance, impact, level

\section{Overend $(\varangle)$}

Faculty of Architecture and the Built Environment, Delft University of Technology, Delft, The Netherlands e-mail: m.overend@tudelft.nl

\section{J. Belis}

Department of Structural Engineering, Ghent University, Ghent, Belgium

e-mail: jan.belis@ugent.be

C. Louter

Institute of Building Construction, Technische Universität Dresden, Dresden, Germany

e-mail: christian.louter@tu-dresden.de

\section{J. H. Nielsen}

Department of Civil Engineering, Technical University of Denmark, Kgs. Lyngby, Denmark

e-mail: jhn@byg.dtu.dk

\section{J. Schneider}

Institute of Structural Mechanics and Design, Technische Universität Darmstadt, Darmstadt, Germany

e-mail: schneider@ismd.tu-darmstadt.de of innovation and clarity of presentation. The authors of the top paper will receive a best paper certificate and a book voucher for springer.com for the value of 100 Euros. The first best paper will be selected from the papers published in 2019 and will be announced at the Challenging Glass Conference Webinar on $4^{\text {th }}$ September 2020. Good luck to all current and future contestants of the GS\&E best paper award!

This issue is no exception to the breadth and depth of the research published in previous issues. The papers in this issue deal with some key topics in this field starting with glass surface / edge quality and coatings such as the paper by Mariggiò et al. (2019) that describes and tests the use of a novel surface coating on glass that increases the bending capacity of the glass; the paper by Malou et al. (2019) that demonstrates the effect of sand blasting on the thermal shock resistance of glass; and the paper by ShivajiRao and Satyanarayana (2019) who investigate abrasive water jet drilling in float glass and demonstrate its limitations when drilling smaller diameter holes in float glass. The other perennial topic in glass engineering is that of connections. This topic is served by the research on the use of spring models to simulate the joint deformation of structural silicone glazing as a simple, yet accurate alternative to finite element analysis by Descamps et al. (2019); and the behaviour of cantilevered laminated glass plates with bolted or adhesively bonded point connections by Quaglini et al. (2020), which among other things finds that the mechanical response is very sensitive to the 
stiffness of the interlayer. This important role of the interlayer leads onto the next paper by D'Ambrosio and Galuppi (2020) who demonstrate how the effective thickness approach may be used to model buckling of laminated glass beams with different boundary conditions. This issue concludes with another recurring topic: Spontaneous cracking of thermally toughened safety glass. In this fourth and final part of their paper Kasper and Rubbert (2020) thermodynamically evaluate an example of an isothermal breakage in a realworld building based on the findings of the preceding three parts that were published in previous editions of this journal.

\section{References}

D'Ambrosio, G., Galuppi, L.: Enhanced effective thickness model for buckling of LG beams with different boundary conditions. Glass Structures \& Engineering (2020). https:// doi.org/10.1007/s40940-019-00116-3

Descamps, P., Van Wassenhove, G., Hayez, V.: Simulating structural silicone glazing joint deformation with spring models. Glass Structures \& Engineering (2019). https://doi.org/10. 1007/s40940-019-00105-6
Kasper, A., Rubbert, F.: Spontaneous cracking of thermally toughened safety glass. Part four: a case study of isothermal breakages in a building, and conclusions thereof for the heat soak test. Glass Structures \& Engineering (2020). https:// doi.org/10.1007/s40940-020-00118-6

Malou, Z., Hamidouche, M., Bouaouadja, N., et al.: Thermal shock resistance of sodalime glass eroded by sandblasting. Glass Structures \& Engineering (2019). https://doi.org/10. 1007/s40940-019-00113-6

Mariggiò, G., Dalle Vacche, S., Bongiovanni, R., et al.: Enhancing the design bending strength of new and aged glass with a functional coating. Glass Structures \& Engineering (2019). https://doi.org/10.1007/s40940-019-00114-5

Quaglini, V., Cattaneo, S., Biolzi, L.: Numerical assessment of laminated cantilevered glass plates with point fixings. Glass Structures \& Engineering (2020). https://doi.org/10.1007/ s40940-020-00119-5

ShivajiRao, M., Satyanarayana, S.: Abrasive water jet drilling of float glass and characterization of hole profile. Glass Structures \& Engineering (2019). https://doi.org/10.1007/ s40940-019-00112-7

Publisher's Note Springer Nature remains neutral with regard to jurisdictional claims in published maps and institutional affiliations. 